\title{
Changes of Serum Ficolin-3 and C5b-9 in Patients with Heart Failure
}

\author{
Hongli $\mathrm{Li}^{1}$, Fangfang Zhang ${ }^{2}$, Dan Zhang ${ }^{3}$, Xiang Tian ${ }^{4}$
}

\begin{abstract}
Objectives: To investigate the correlation of serum ficolin-3 and C5b-9 with cardiac function and NTproBNP in patients with heart failure.

Methods: Sixty patients with heart failure admitted to the Baoding First Central Hospital from May 2019 to May 2020 were selected and divided into three groups according to the classification of New York Heart Association (NYHA). Patients with NYHA grade II, III, and IV were included into group A, B, and C, respectively. Among the population undergoing physical examination at the same time, 20 cases with no significant difference in age and gender from the experimental group were selected as the control group (Group-N), and their clinical data were recorded. The serum levels of ficolin-3, C5b-9 and NT-proBNP in each group were detected and compared.

Results: The serum concentrations of ficolin-3 and C5b-9 in Group N were significantly different from those in Group A, B and C ( $<<0.05)$, the difference between Group C and Group A and B was statistically significant $(p<0.05)$, there was no significant difference between group $A$ and $B(p>0.05)$. The correlation analysis between serum ficolin-3 and NT-proBNP showed that serum ficolin-3 was negatively correlated with NT-proBNP $(r=-0.606, p<0.0001)$, while the correlation analysis between serum C5b-9 and NT-proBNP showed that serum C5b-9 was positively correlated with NT-proBNP $(r=0.499, p<0.0001)$. According to the etiology of heart failure, patients with heart failure were divided into coronary heart disease ( 25 cases), dilated cardiomyopathy (15 cases) and others (20 cases). The differences of ficolin-3 and C5b-9 among patients were compared, and there was no statistical difference $(p<0.05)$.

Conclusion: Ficolin-3 was inversely associated with the severity of heart failure, while C5b-9 was positively associated with the severity of cardiac impairment. Both of them have nothing to do with the etiology of heart failure.
\end{abstract}

KEYWORDS: Ficolin-3, C5b-9, Heart failure.

doi: https://doi.org/10.12669/pjms.37.7.4151

How to cite this:

Li H, Zhang F, Zhang D, Tian X. Changes of Serum Ficolin-3 and C5b-9 in Patients with Heart Failure. Pak J Med Sci. 2021;37(7):1860-1864. doi: https://doi.org/10.12669/pjms.37.7.4151

This is an Open Access article distributed under the terms of the Creative Commons Attribution License (http://creativecommons.org/licenses/by/3.0), which permits unrestricted use, distribution, and reproduction in any medium, provided the original work is properly cited.

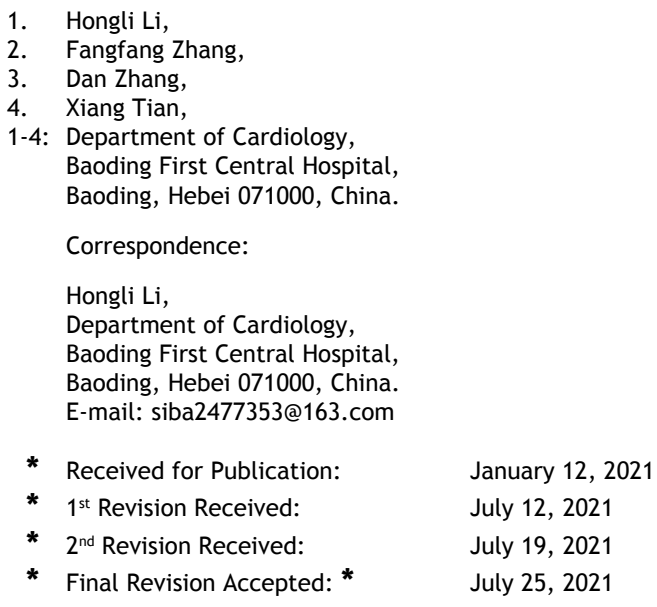

\section{INTRODUCTION}

Heart failure (HF) is the common end of a variety of heart diseases, ${ }^{1}$ which seriously threatens human health. It has been shown in a large number of studies that complement exerts an important role in the occurrence and development of $\mathrm{HF}^{2-5}$ Ficolin-3 is a promoter of the complement lectin pathway, which can activate the lectin pathway of complement so that the complement system is fully activated, and the terminal complement complex C5b-9 is eventually formed. Studies have shown that the reduction of serum ficolin-3 levels has a close bearing on a variety of cardiovascular diseases. ${ }^{3}$ According to foreign studies on Bulgarian 
and Norwegian races, ficolin-3 is associated with heart failure, ${ }^{4}$ but few studies have been carried out in China on ficolin-3 in heart failure, and most of the studies on ficolin-3 have focused on autoimmune system and inflammation and other diseases. Instead, most of the studies on ficolin-3 have focused on diseases such as autoimmune system and inflammation..$^{6-8}$ In this study, the role of ficolin-3 and C5b-9 in heart failure was studied to explore the relationship between ficolin-3 and C5b9 and cardiac function in patients with heart failure, so as to provide new methods for the diagnosis and prognosis of heart failure, and to conceive new treatment ideas and schemes for delaying the progression of heart failure.

\section{METHODS}

Patients with heart failure with ejection fraction less than 0.45 admitted to the Department of Cardiology, Baoding First Central Hospital between May 2019 and May 2020 underwent routine echocardiography, and their ejection fraction, E/A value, left ventricular end-systolic diameter, and left ventricular end-diastolic diameter were recorded. The study subjects were determined by medical history, symptoms, signs, and cardiac color Doppler ultrasound results, and were divided into three groups according to the NYHA functional classification: Group-A, Group-B and Group-C. Among them, 20 patients with NYHA-II were divided into Group-A, 20 patients with NYHA-II were included into Group-B, and 20 patients with NYHA-IV were included into Group-C. Among the population undergoing physical examination, 20 cases with no significant difference in age and gender from the experimental group were selected as the control group (Group-N).

Inclusion criteria: Based on the 2012 European Society of Cardiology Guidelines for the Diagnosis and Treatment of Acute and Chronic Heart Failure:

- Typical symptoms of heart failure;

- Typical signs of heart failure;

- Decreased left ventricular ejection fraction. Patients need to meet the above three criteria to be included.

Exclusion criteria:

- Patients with acute or chronic inflammatory diseases and immune system diseases;

- Patients with pregnancy, severely impaired liver and kidney function;

- Patients with acute cerebrovascular disease and malignant tumor;

- Patients with acute coronary syndrome, congenital heart disease, and other serious complications. This study was approved by the Ethics Committee of Baoding First Central Hospital, (January 13, 2021) and all the subjects signed the informed consent form.

Clinical data collection: The clinical data of each group were recorded, including age, gender, blood lipid, NYHA heart function classification, primary disease, smoking history, alcohol history and general clinical data.

Serological index detection: In the early morning of the next day after admission, $4 \mathrm{ml}$ of fasting elbow venous blood was collected from the patients who met the diagnostic criteria and centrifuged for $20 \mathrm{~min}(3000 \mathrm{r} / \mathrm{min})$ after standing. The serum was separated and transferred into the freezing tube. After labeling, the samples were frozen at $-70^{\circ} \mathrm{C}$. All samples were collected for detection at one time. The human ficolin-3 kit provided by Nanjing Jiancheng Research Institute was used to detect the serum ficolin-3 level by enzyme-linked immunosorbent assay. The sensitivity of the kit: $1.0 \mathrm{ug} / \mathrm{ml}$, strong specificity, detection value range: $0-160 \mathrm{ug} / \mathrm{ml}$. The testing process was operated in strict accordance with the instructions. Serum C5b-9 was measured by ELISA kit of human terminal complement complex C5b-9 provided by Nanjing Jiancheng Research Institute. The sensitivity and specificity: $1.0 \mathrm{ng} / \mathrm{ml}$, strong specificity, detection value range: $0-2000 \mathrm{ng} / \mathrm{ml}$. The testing process was operated in strict accordance with the instructions. NT proBNP was measured by the Department of Laboratory Medicine, Baoding First Central Hospital.

Statistical Processing: SAS statistical software was used for data processing, and the experimental data was expressed as mean \pm standard deviation. $T$ test was adopted for inter-group data comparison, linear correlation analysis was used to analyze the correlation between the two groups, and analysis of variance was used for the comparison between the two groups. $\mathrm{P}<0.05$ indicates a statistically significant difference.

\section{RESULTS}

No significant difference could be seen between the control group (normal healthy group) and the experimental group (heart failure group) in terms of average age, gender, hypertension, diabetes, smoking, drinking and other general clinical data, and there was no statistical significance. $(p>0.05)$ (Table-I).

The concentration of serum ficolin-3 in Group-N was $27.760 \pm 14.835 \mathrm{ug} / \mathrm{ml}$, that in Group-A 
Serum Ficolin-3 and C5b-9 in Patients with Heart Failure

Table-I: Basic information of subjects.

\begin{tabular}{lcccc}
\hline & Group-N & Group-A & Group- & Group-C \\
\hline The number of cases & 20 & 20 & 20 & 20 \\
Age & $61 \pm 12.53$ & $64 \pm 11.46$ & $62.65 \pm 16.22$ & $64.35 \pm 12.22$ \\
Gender (male/female) & $10 / 10$ & $9 / 11$ & $10 / 10$ & $10 / 10$ \\
Smoking (\%) & $6(30 \%)$ & $5(25 \%)$ & $5(25 \%)$ & $6(30 \%)$ \\
Hypertension $(\%)$ & -- & $10(50 \%)$ & $11(55 \%)$ & $12(60 \%)$ \\
Diabetes (\%) & -- & $7(35 \%)$ & $5(25 \%)$ & $8(40 \%)$ \\
CHOL (mmol/l) & $4.19 \pm 0.8$ & $3.96 \pm 1.20$ & $3.72 \pm 1.11$ & $4.35 \pm 1.21^{*}$ \\
TG (mmol/l) & $1.63 \pm 0.53$ & $1.34 \pm 0.75$ & $1.18 \pm 0.48^{*}$ & $1.06 \pm 0.31^{*}$ \\
HDL (mmol/l) & $0.91 \pm 0.16$ & $1.0 \pm 0.29$ & $0.93 \pm 0.21$ & $1.01 \pm 0.27$ \\
LDL (mmol/l) & $2.59 \pm 0.68$ & $2.61 \pm 0.88$ & $2.57 \pm 0.93$ & $3.19 \pm 1.01^{*}$ \\
ALT (u/l) & $21.84 \pm 8.01$ & $24.7 \pm 8.08$ & $30.21 \pm 28.34$ & $34.78 \pm 32.80$ \\
AST (u/l) & $22.66 \pm 14.21$ & $20.15 \pm 6.38$ & $38.67 \pm 61.31$ & $40.71 \pm 40.8$ \\
Cr (umol/l) & $59.37 \pm 7.65$ & $56.5 \pm 10.06$ & $71.07 \pm 35.48$ & $80.62 \pm 66.06$ \\
LVDD (mm) & -- & $54.35 \pm 6.41^{*}$ & $59.9 \pm 6.33^{*}$ & $67.5 \pm 12.16^{*}$ \\
Peak E (m/s) & -- & $0.94 \pm 0.42$ & $0.89 \pm 0.47$ & $0.88 \pm 0.24$ \\
Peak A (m/s) & -- & $0.69 \pm 0.21$ & $0.63 \pm 0.26$ & $0.65 \pm 0.31$ \\
LVEF $(\%)$ & -- & $41.3 \pm 4.55$ & $37.1 \pm 6.99$ & $34.3 \pm 8.65^{*}$ \\
\hline
\end{tabular}

Note: ${ }^{*} \mathrm{p}<0.05$.

was $17.896 \pm 1.308 \mathrm{ug} / \mathrm{ml}$, that in Group-B was $16.096 \pm 0.94 \mathrm{ug} / \mathrm{ml}$, and that in Group-C was $11.197 \pm 1.899 \mathrm{ug} / \mathrm{ml}$. In terms of pairwise comparison between groups, Group-N was statistically different from groups $\mathrm{A}, \mathrm{B}$, and $\mathrm{C}$ $(p<0.05)$, Group- $C$ was statistically different from Group-A and Group-B $(p<0.05)$, but there was no statistical difference between Group-A and Group-B ( $p>0.05)$. (Table-II and Fig.1)

The concentration of serum C5b-9 in Group-N was $87.397 \pm 54.011 \mathrm{ng} / \mathrm{ml}$, that in Group-A was $233.759 \pm 17.659 \mathrm{ng} / \mathrm{ml}$, that in Group-B was $320.793 \pm 34.956 \mathrm{ng} / \mathrm{ml}$, and that in Group-C was $658.657 \pm 366.514 \mathrm{ng} / \mathrm{ml}$. In terms of pairwise comparison between groups, Group-N was statistically different from groups A, B, and C $(p<0.05)$, Group- $C$ was statistically different from Group-A and Group-B $(p<0.05)$, but there was no statistical difference between Group-A and Group-B ( $>>0.05)$. (Table-II and Fig.2)

The concentration of serum NT-proBNP in Group-A was $579.800 \pm 232.091 \mathrm{pg} / \mathrm{ml}$, that in Group-B was $3944.950 \pm 1126.130 \mathrm{pg} / \mathrm{ml}$, and that in Group-C was $16572.200 \pm 10775.192$ pg/ml. In terms of pairwise comparison between groups,

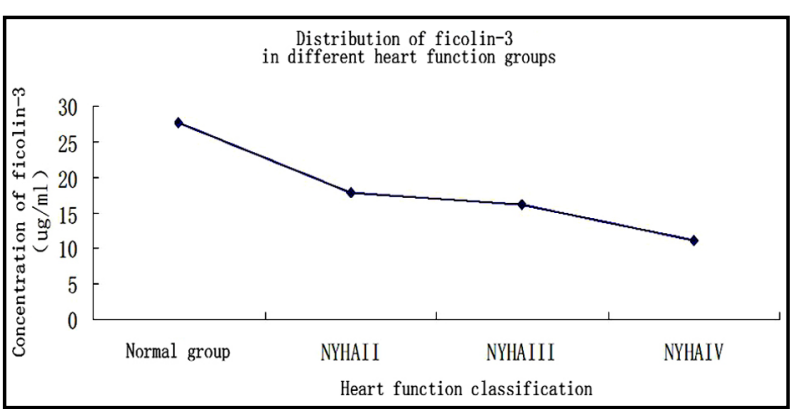

Fig.1: Concentration of serum ficolin-3 in each group.

Table-II: Concentrations of experimental indexes in each group.

\begin{tabular}{cccc}
\hline & NT-proBNP(pg/ml $)$ & Ficolin-3(ug/ml $)$ & C5b-9(ng/ml $)$ \\
\hline Group-N & -- & $27.760 \pm 14.835$ & $87.397 \pm 54.011$ \\
Group-A & $579.800 \pm 232.091$ & $17.896 \pm 1.308$ & $233.759 \pm 17.659$ \\
Group-B & $3944.950 \pm 1126.130$ & $16.096 \pm 0.94$ & $320.793 \pm 34.956$ \\
Group-C & $16572.200 \pm 10775.192^{*}$ & $11.197 \pm 1.899^{*}$ & $658.657 \pm 366.514^{*}$ \\
\hline
\end{tabular}

Note: ${ }^{*} \mathrm{p}<0.05$. 


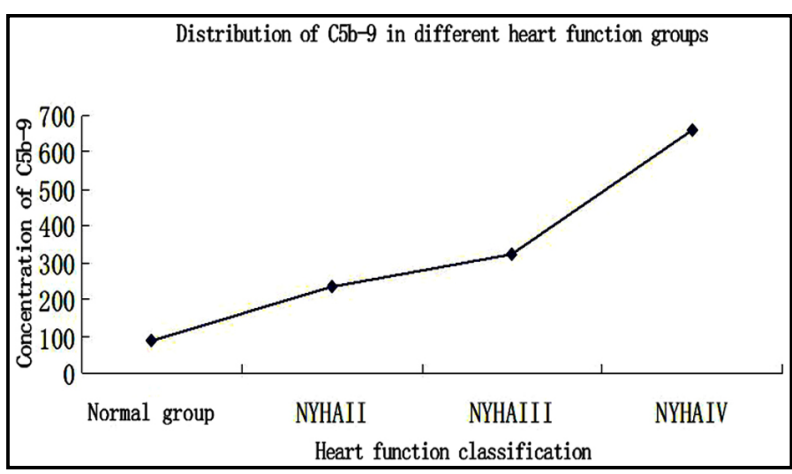

Fig.2: Concentration of $\mathrm{C} 5 \mathrm{~b}-9$ in each group.

Group-C was statistically different from Group-A and Group-B $(\mathrm{p}<0.05)$, but there was no statistical difference between Group-A and Group-B $(p>0.05)$, as shown in Table-II and Fig.3. Ficolin-3 was significantly negatively correlated with NTproBNP $(r=-0.606, p<0.0001)$, as shown in Fig.4. C5b-9 was significantly positively correlated with NT-proBNP $(\mathrm{r}=0.499, \mathrm{p}<0.0001)$, as shown in Fig.5.

According to the etiology of heart failure, heart failure was divided into coronary heart disease group, dilated cardiomyopathy group and other, and the relationship between ficolin-3, C5b-9 and NT-proBNP was compared among the three groups, as shown in Table-III. It can be seen from Table-III that there was no statistical difference between the groups, that is, ficolin-3 and C5b-

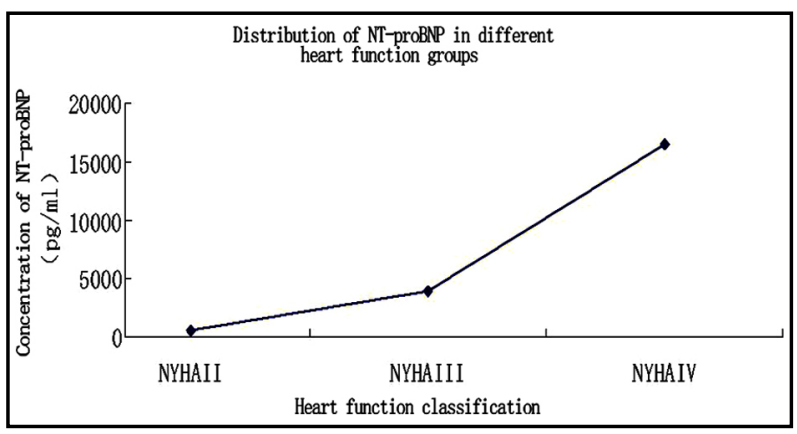

Fig.3: Concentration of serum NT-proBNP in the experimental group.

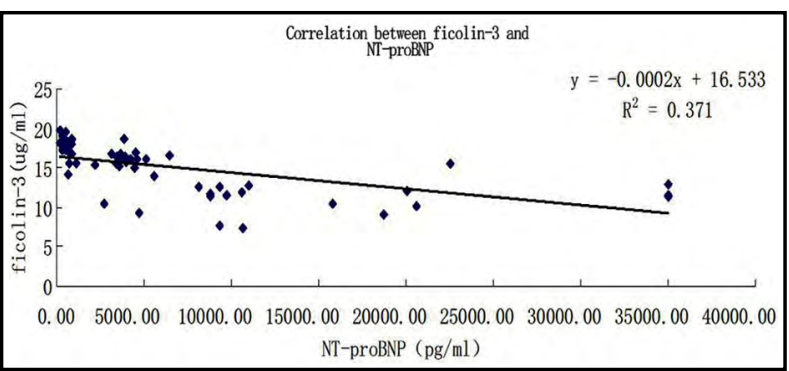

Fig.4: Correlation analysis between ficolin-3 and NT-proBNP.

9 have nothing to do with the etiology of heart failure, but are only linked to the severity of heart failure.

\section{DISCUSSION}

Cardiomyocytes in patients with heart failure are characterized by a variety of death mechanisms, including necrosis, apoptosis, tumor and autophagy, etc., which are related to complement activation. ${ }^{9-11}$ The relationship between complement activation and heart failure is further supported by a study by Prohászka et al. ${ }^{4}$ According to this study, after long-term circulatory support, the deposition of the terminal complement complex C5b-9 in the cardiomyocytes of heart failure increased significantly, and C5b9 leads to cardiomyocyte necrosis via various mechanisms ${ }^{12}$ and aggravates heart failure.

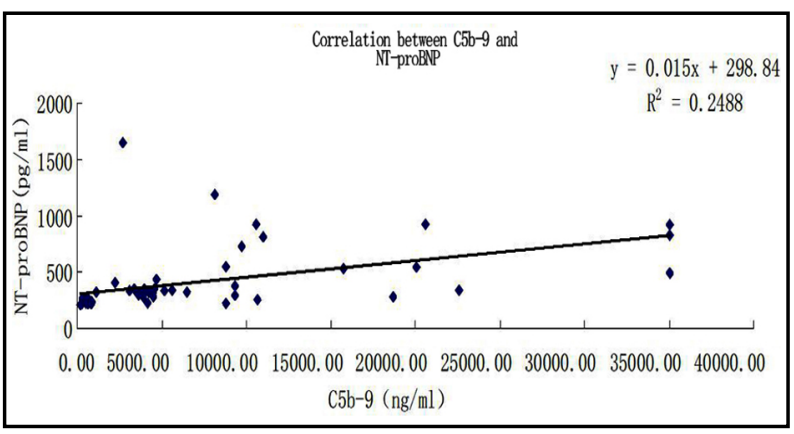

Fig.5: Correlation analysis between C5b-9 and NT-proBNP.

Table-III: Comparison between different etiologies.

\begin{tabular}{lccc}
\hline Etiology & Ficolin-3 $(\mathrm{ug} / \mathrm{ml})$ & C5b-9(ng/ml) & NT-proBNP $(\mathrm{pg} / \mathrm{ml})$ \\
\hline Coronary heart disease $(\mathrm{n}=25)$ & $14.92 \pm 3.55$ & $354.07 \pm 168.28$ & $4510.29 \pm 8106.68$ \\
Dilated heart disease $(\mathrm{n}=15)$ & $15.07 \pm 2.81$ & $481.63 \pm 402.56$ & $3875 \pm 6446.19$ \\
Other $(\mathrm{n}=20)$ & $15.22 \pm 3.08$ & $412.85 \pm 288.26$ & $2053.21 \pm 1745.90$ \\
F value & 0.05 & 0.95 & 0.62 \\
$\mathrm{P}$ & 0.9514 & 0.3927 & 0.5413 \\
\hline
\end{tabular}


NT-proBNP is the gold standard for the diagnosis of heart failure, and can be used to determine the prognosis of heart failure. ${ }^{13}$ In this experiment, the correlation analysis between ficolin-3 and NTproBNP shows that ficolin-3 is negatively correlated with NT-proBNP, indicating that ficolin-3 is likely to be used as a new index for the prognosis of heart failure. Ficolin-3 is easier to determine in serum, and the determination method is constantly simplified. Moreover, ficolin-3 may be widely used in heart failure like NT-proBNP in the future with more and more in-depth and extensive research on ficolin-3.

It is also shown by the results of this study that C5b-9 is significantly positively correlated with NT-proBNP in patients with heart failure $(p<0.0001)$, indicating that complement activation exists in patients with heart failure and is involved in the continuous progress of heart failure. This result is consistent with the theory of the role of complement in heart failure ${ }^{14}$ and demonstrates the positive role that complement activation plays in the progression of heart failure. Based on this, complement may open up a new field for the study of methods to delay heart failure, and become a new target for the treatment of heart failure.

Limitations and Prospects of the study: Ficolin-3 and C5b-9 have been proved to be correlated with heart function in patients with heart failure in this experiment, but fewer cases were included in this experiment. At the same time, studies odoin the specific action pathways and mechanisms of ficolin-3 and C5b-9 have not yet been carried out, and only macroscopically, the concentration is taken as the measurement standard and the object of comparison. Therefore, further research needs to be carried out in this aspect to clarify the action pathways and mechanisms of ficolin-3 and C5b-9.

\section{Declaration of conflicting interest: None.}

Source of Funding: The study was sponsored by Baoding Science and Technology Plan Project (1941ZF045).

\section{REFERENCES}

1. Chen $\mathrm{ZY}, \mathrm{Hu}$ YS. Poor r-wave progression in elderly patients with chronic bilateral heart failure and left bundle branch block. Chinese J Pract Diagn Ther. 2019;33(7):682-684.
2. Egorova EN, Kalinkin MN, Mazur ES. Endotoxinemia and systemic inflammation in pathogenesis of chronic heart failure. Patol Fiziol Eksp Ter. 2011;(4):42-46.

3. Pan JW, Gao XW, Jiang H, Li YF, Xiao F, Zhan RY. Low serum ficolin-3 levels are associated with severity and poor outcome in traumatic brain injury. J Neuroinflammation. 2015;12:226. doi: 10.1186/s12974-015-0444-z

4. Prohászka $Z$, Munthe-Fog L, Ueland $T$, Gombos $T$, Yndestad A, Forhecz Z, et al. Association of ficolin-3 with severity and outcome of chronic heart failure. PLoS One. 2013;8(4):e60976. doi: 10.1371/journal.pone.0060976

5. Carter AM. Complement activation: an emerging player in the pathogenesis of cardiovascular disease. Scientifica (Cairo). 2012;2012:402783. doi: 10.6064/2012/402783

6. Michalski M, Świerzko AS, Sawicki S, Kałużyński A, Łukasiewicz J, Maciejewska A, et al. Interactions of ficolin-3 with ovarian cancer cells. Immunobiology. 2019;224(2):316-324. doi: 10.1016/j.imbio.2019.01.002

7. Yuan XS, Shi H, Wang HY, Yu B, Jiang J. Ficolin-3/ adiponectin ratio for the prediction of gestational diabetes mellitus in pregnant women. J Diabetes Investig. 2018;9(2):403-410. doi: 10.1111/jdi.12688

8. Andrade FA, Beltrame MH, Bini VB, Gonçalves LB, Boldt $A B$, de Messias-Reason IJ. Association of a new FCN3 haplotype with high ficolin-3 levels in leprosy. PLoS Negl Trop Dis. 2017;11(2):e0005409. doi: 10.1371/journal. pntd.0005409

9. Whelan RS, Kaplinskiy V, Kitsis RN. Cell death in the pathogenesis of heart disease: mechanisms and significance. Annu Rev Physiol. 2010;72:19-44. doi: 10.1146/annurev. physiol.010908.163111

10. Konstantinidis K, Whelan RS, Kitsis RN. Mechanisms of cell death in heart disease. Arterioscler Thromb Vasc Biol. 2012;32(7):1552-1562. doi: 10.1161/ATVBAHA.111.224915

11. Del Re DP, Amgalan D, Linkermann A, Liu Q, Kitsis RN. Fundamental Mechanisms of Regulated Cell Death and Implications for Heart Disease. Physiol Rev. 2019;99(4):1765-1817. doi: 10.1152/physrev.00022.2018

12. Wrigley BJ, Lip GY, Shantsila E. The role of monocytes and inflammation in the pathophysiology of heart failure. Eur J Heart Fail. 2011;13(11):1161-1171. doi: 10.1093/eurjhf/ hfr122

13. Darche FF, Baumgartner C, Biener M, Muller-Hennessen M, Vafaie M, Koch V, et al. Comparative accuracy of NTproBNP and MR-proANP for the diagnosis of acute heart failure in dyspnoeic patients. ESC Heart Fail. 2017;4(3):232240. doi: 10.1002 /ehf 2.12150

14. Jaipersad AS, Lip GY, Silverman S, Shantsila E. The role of monocytes in angiogenesis and atherosclerosis. J Am Coll Cardiol. 2014;63(1):1-11. doi: 10.1016/j.jacc.2013.09.019

\section{Authors' Contributions:}

HL \& FZ: Designed this study and prepared this manuscript, and are responsible and accountable for the accuracy or integrity of the work.

DZ: Collected and analyzed clinical data. XT: Significantly revised this manuscript. 